\title{
MATEj ŠEKLI
}

\section{POMENSKA POLJA NEMŠKIH IZPOSOJENK} V SLOVENŠČINI

COBISS: 1.02

V prispevku so slovensko-nemški jezikovni stiki postavljeni v širši kontekst slovansko-germanskih jezikovnih stikov in so prikazana pomenska polja nemških izposojenk v slovenščini. Na osnovi glasovnih značilnosti slednjih so določeni geolekt (zemljepisna različica) in sociolekt (družbena različica) ter njun hronolekt (časovna različica) nemščine, iz katerega je bila posamezna beseda prevzeta v slovenščino. Glasoslovna in pomenoslovna analiza nemških izposojenk v slovenščini je osnova za določitev področij človeške kulture, na katerih je nemška kultura $\mathrm{v}$ različnih zgodovinskih obdobjih vplivala na slovensko kulturo.

Ključne besede: stično jezikoslovje, jeziki v stiku, nadomestno glasoslovje, pomenoslovje, (južno)bavarska visoka nemščina, slovenščina

\section{Semantic fields of German loanwords in Slovenian}

This article discusses the semantic fields of German loanwords in Slovenian. Slovenian-German language contact is placed into the broader context of Slavic-Germanic language contacts. On the basis of phonological characteristics of German loanwords in Slovenian, the relevant geolect (i.e. the geographic variant), the sociolect (i.e. the social variant), and the chronolect (i.e. the temporal variant) of the German source is determined. Both phonological and semantic analyses of German loanwords in Slovenian help expose the spheres of human culture in which German culture exerted its influence on Slovenian culture throughout various historical periods.

Keywords: contact linguistics, language contact, substitutional phonology, semantics, (South) Bavarian High German, Slovenian

\section{SLOVENSKO-NEMŠKI JEZIKOVNI STIK V SLOVANSKO- -GERMANSKEM KONTEKSTU}

Slovensko-nemški jezikovni stiki, in sicer predvsem vpliv nemščine na slovenščino, so postavljeni v širši kontekst starih slovansko-germanskih jezikovnih stikov oz. vplivov germanskih jezikov na slovanske v najstarejših obdobjih.1

1 Nemške izposojenke $\mathrm{v}$ ljudski in knjižni slovenščini so bile doslej najbolj natančno obdelane slovarsko (Stiedter-Temps 1963; Jazbec 2007; ESSJ I-IV; Snoj 2003). V okviru študija jezikov v stiku so bile obravnavane nemške izposojenke v koroških slovenskih narečjih (Bayer 2006: 64-82). Pričujoči prispevek temelji predvsem na gradivu v Striedter-Temps 1963. 


\subsection{Germanizmi v slovanskih jezilkih}

Germanizme v slovanskih jezikih je s stališča germanskega idioma, iz katerega so bili prevzeti, in s stališča slovanskega idioma, v katerega so bili prevzeti, mogoče razdeliti na starejše in mlajše.

Starejši germanizmi so bili iz starih germanskih jezikov prevzeti v praslovanščino (do ok. 800 n. š.). Govorci praslovanščine so pred razselitvijo iz pradomovine severno od Karpatov (do ok. 500 n. š.) besedje prevzemali morda že iz pragermanščine, vsekakor iz gotščine, po razselitvi iz pradomovine (od ok. 500 n. š.) pa iz zahodne germanščine oz. iz že izoblikovanih starih zahodnogermanskih jezikov, najverjetneje iz stare visoke nemščine. ${ }^{2}$

Mlajši germanizmi so bili iz germanskih jezikov oz. njihovih zemljepisnih in časovnih različic prevzeti v posamezne slovanske jezike (od ok. 800 n. š.). Južnoslovanski jeziki so prevzemali iz visoke nemščine, zahodnoslovanski jeziki iz visoke in spodnje nemščine, vzhodnoslovanski jeziki predvsem iz skandinavskih jezikov. Med mlajše germanizme v slovanskih jezikih spadajo tudi t. i. nemcizmi, tj. nemške izposojenke $v$ slovenščini. ${ }^{3}$

\subsection{Visoka nemščina v stiku s slovenščino}

Pri preučevanju jezikovnega stika visoke nemščine s slovenščino je treba upoštevati različne zemljepisne, družbene in časovne jezikovne različice jezika dajalca:

[a] diatopični vidik: v ozemeljskem stiku s slovenščino se pojavlja samo en nemški geolekt (zemljepisna različica), in sicer (južna) bavarska visoka nemščina;

[b] diastratični vidik: v družbenem stiku s slovenščino se pojavljata vsaj dva nemška sociolekta (družbeni različici), in sicer (južno)bavarska narečna visoka nemščina in knjižna visoka nemščina, katere narečna osnova je frankovska visoka nemščina;

[c] diahron(ičn)i vidik: v časovnem stiku s slovenščino se pojavlja več hronolektov (časovnih različic) (južno)bavarske visoke nemščine, saj se je ta v času neprestano spreminjala, zato je mogoče ločiti več njenih hronolektov: to so stara, srednja in nova (južno)bavarska visoka nemščina.

Poudarek obravnave je na obdobju visokega in poznega srednjega veka, saj se je $\mathrm{v}$ tem času pod vplivom nemščine podoba slovenskega besedja korenito spremenila. 4

2 Starejši germanizmi v praslovanščini so natančno obravnavani npr. v Kiparsky 1934 in Pronk-Tiethoff 2012. Pregledni prikaz je podan v Šekli 2014: 287-288, 294-296, 298.

$3 \quad$ Mlajši germanizmi v slovanskih jezikih na gradivu Slovanskega jezikovnega atlasa so monografsko obdelani npr. v Siatkowski 2004; 2005.

4 Jazbec 2007: 100; Furlan 2014: 27. 


\section{STAROGERMANSKE IZPOSOJENKE V PRASLOVANŠČINI}

Starogermanske izposojenke so bile iz starih germanskih jezikov prevzete $\mathrm{v}$ praslovanščino (do ok. 800 n. š.). Gre za podedovano besedje, tj. besedje germanskega izvora, ali pa besedje, prevzeto iz latinščine v pragermanščino oz. enega od že izoblikovanih germanskih jezikov. Na osnovi predvsem glasovne analize starogermanskih izposojenk $\mathrm{v}$ praslovanščini in študija nadomestnega glasoslovja, tj. kateri germanski glas se nadomesti s katerim slovanskim glasom, je mogoče reči, da starogermanske izposojenke v praslovanščini izvirajo iz gotščine (iz obdobja ok. 150-375 n. š.) ali iz zahodnogermanskih jezikov (iz obdobja ok. 500-800 n. š.), pri čemer bi lahko bil del besedja glede na glasovne značilnosti prevzet iz obeh virov.

\subsection{Gotske izposojenke v praslovanščini}

Prvi slovansko-gotski jezikovni stiki najverjetneje segajo v 1. stoletje pr. n. š., ko so bili Goti še v svoji germanski pradomovini, v 1. tisočletju pr. n. š. so se namreč iz prvotnega germanskega poselitvenega jedra ob spodnjem toku Labe in Odre razširili na vzhod ob spodnji tok reke Visle. Goti so postali neposredni sosedi Slovanov v 2. stoletju n. š. po preselitvi z obale Baltskega morja (preko slovanskega preselitvenega prostora) na severno oz. severozahodno obalo Črnega morja ob spodnji tok Dnepra (vzhodni Goti) oz. Donave (zahodni Goti), kjer so ustanovili svojo državo in se pokristjanili (Wulfilov prevod biblije v (zahodno) gotščino je nastal ok. 350 n. š.). 5 Konec slovansko-gotskih stikov je mogoče datirati približno $\mathrm{v}$ čas po propadu (zahodno)gotske države zaradi vdora Hunov v Evropo leta 375 n. š.

Za gotske izposojenke $\mathrm{v}$ praslovanščini so značilne naslednja pravila nadomestnega glasoslovja: (a) samoglasniki: got. $\bar{e} \rightarrow$ psl. ${ }^{*} \check{e}_{1}$ (psl. *lěkz); got. aiC $\rightarrow$ psl. ${ }^{*} \check{e}_{2} C$ (psl. *xlébr, $\left.{ }^{*} x l e \check{v} v\right)$; got. $i u C \rightarrow$ psl. ${ }^{*} j u_{2} C$ (psl. *bludz); got. auC $\rightarrow$ psl. ${ }^{*} u_{2} C$ (psl. *kupiti, *kusiti); got. ENC, ONC $\rightarrow$ psl. *ęC, * ${ }^{*} C$ (psl. *usbręzb, $\left.{ }^{*} x o s a\right) ; 6$ got. $\bar{u} \rightarrow$ psl. *y (psl. *xyzъ/*xyza); got. $i, u \rightarrow$ psl. ${ }^{*} b,{ }^{*}{ }^{*}$ (psl. * stbklo, $*_{x ъ l m ъ}$ ); got. $a \rightarrow$ psl. ${ }^{*} o$ (psl. *kotbl,${ }^{*}$ osblb); (b) soglasniki: got. $h^{E} \rightarrow$ psl. $*_{s}$ (psl. *šelmb, *šatb); got. kaiC $\rightarrow$ psl. *cěC (psl. *cěsaŕb); got. ing, ig $\rightarrow$ psl. *ez, ${ }^{*}$ b3 (psl. *userezb, *gobbzb); got. $f \rightarrow$ psl. *p (psl. *pslkъ); got. $s, *_{z} \rightarrow$ psl. $*_{s}, *_{z}$ (psl. *usbrezb, *goneznoti). Besedje iz gotščine v praslovanščino je bilo prevzeto pred oblikovanjem poznopraslovanskega glasovnega sistema.7

$5 \quad$ Preden je bila gotščina dokumentirana, je bila torej že dve stoletji v stiku s praslovanščino. Posledično je treba upoštevati tudi spreminjanje gotščine v obdobju od 2. do 4. stoletja n. š. (npr. glasovno spremembo got. ${ }^{*} e>i$ ).

6 Simbol *E označuje sprednje samoglasnike, simbol $* O$ nesprednje samoglasnike, simbol $* N$ nosna soglasnika $*_{m}, *_{n}$, simbol $*_{C}$ ostale soglasnike.

$7 \quad \mathrm{~V}$ času prevzema iz gotščine $\mathrm{v}$ praslovanščini npr. še ni prišlo do praslovanske monoftongizacije diftongov in do praslovanskih palatalizacij velarov v položaju pred sprednjimi samoglasniki ali za njimi (psl. *xelmъ > *šelmъ, *kaisaŕr $>$ *kěsaŕb $>*$ cěsaŕb, *usbręgъ $>*$ usbręzb). 
Gotske izposojenke v praslovanščino izkazujejo tale pomenska polja:8

[a] oblast in vojska: got. kaisar 'cesar' $\rightarrow$ psl. *cěsaŕb 'vladar, kralj, cesar' $(>\sin$. césar); got. *fulka *'množica vojakov, truma' (izpričano v lastnih imenih zgot.

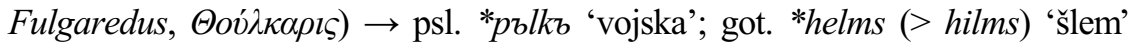
$\rightarrow$ psl. *šelmъ 'šlem'; got. hansa ‘truma, množica, spremstvo' $\rightarrow$ psl. *xosa 'zaseda, tatvina'; got. *ganesan (> ganisan) 'okrevati, biti rešen' $\rightarrow$ psl. *goneznoti 'osvoboditi se, ubežati', got. ganasjan 'povzročiti' $\rightarrow$ psl. *gonoziti 'osvoboditi';

[b] trgovina in denar: got. kaupōn 'trgovati' $\rightarrow$ psl. *kupiti 'kupiti' (> sln. kupīti); got. kintus 'vinar' $\rightarrow$ psl. 'cęta 'drobiž'; got. leiha 'posojilo' $\rightarrow$ psl. *lixva 'dajatev'; got. lèkeis 'zdravnik' $\rightarrow$ psl. *lěks 'zdravilo' (> sln. lệk); got. skatts 'denar' $\rightarrow$ psl. *skotb 'živina, govedo'; got. asilus 'osel' $\rightarrow$ psl. *osblb 'osel' (> sln. ósal); got. *hēt- 'obleka' $\rightarrow$ psl. *šatı, *šata 'obleka, pokrivalo'; 9 got. stikls 'kozarec, skodelica' $\rightarrow$ psl. *stbklo 'steklo'; got. *ausihriggs 'uhan' $\rightarrow$ psl. *usbręzb 'uhan';

[c] predmeti za shranjevanje: got. biups, biuda- 'miza' $\rightarrow$ psl. *bluds 'posoda, skleda'; got. *katils (Gpl katilē) 'kotel' $\rightarrow$ psl. *kotblb 'kotel' (> sln. kótal);

[č] deli naselij, stavbe in imetje: got. (gud-)hūs 'božja hiša, tempelj' $\rightarrow$ psl. * $x y z b / * x y-$ $z a$ 'hiša'; got. hlaiw 'grob' $\rightarrow$ psl. *xlěvb 'hlev' (> sln. hlẹv);

[d] drugo: got. gabei, Gsg gabeins 'bogastvo' $\rightarrow$ psl. *gobino, *gobina 'bogastvo, obilje'; got. gabigs 'bogat' $\rightarrow$ psl. *gobbzb 'obilen'; got. hlaifs, hlaiba- 'kruh' $\rightarrow$ psl. *xlěbs 'kruh' (> sln. hlẹb/hlëb); got. *hulms *'vzpetina' $\rightarrow$ psl. *xъlmъ 'holm, grič' (> sln. họlm); got. handugs 'moder, pameten' $\rightarrow$ psl. *xodogb 'izkušen'; got. kausjan 'pokušati, preizkusiti (hrano)' $\rightarrow$ psl. *kusiti 'poskusiti, pokušati' (> sln. -kúsiti); got. faírguni 'gora, gorovje' $\rightarrow$ psl. *pergyni, Gsg *pergyńę (psl. *-yni ob naslonitvi na tip *bogyni 'boginja', *pustyni 'pustinja, puščava').

\subsection{Zahodnogermanske izposojenke v praslovanščini}

Slovani so v stik z zahodnimi Germani prišli v 6. stoletju n. š., ko so poselili vzhodni del srednje in jugovzhodno Evropo. Novo slovansko poselitveno ozemlje je na zahodu segalo do Labe in Sale preko Donave čez vzhodne Alpe (na zahodu do izvira Drave) do Tržaškega zaliva na jugu. Zahodni sosedi praslovanščine sta tako postali takrat še oblikujoči se stara spodnja nemščina (stara saščina) (izpričana v obdobju ok. 800-1100) ter (frankovska in bavarska) stara visoka nemščina (izpričana v obdobju ok. 750-1050).10

8 O pomenski delitvi germanskih izposojenk v praslovanščini v zadnjem času prim. PronkTiethoff 2010: 321-324.

$9 \quad$ Kljub temu da leksem *hēt- v gotščini ni izpričan, stvn. $h \bar{a} 3$ kot vir izposoje ne pride v poštev, saj izkazuje zahodnogermansko-severnogermanski prehod $*_{\bar{e}}>\bar{a}$.

10 Stara spodnja nemščina (stara saščina) in stara visoka nemščina sta bili pred dokumentacijo skoraj dve stoletji v stiku s praslovanščino. Do večje jezikovne diferenciacije med spodnjo in visoko nemščino je prišlo šele $\mathrm{z}$ drugim (starovisokonemškim) premikom soglasnikov ok. 750 n. š. (npr. stsaš. budin : stvn. *budin > butin). Slovani so besedje iz zahodne germanščine prevzemali že pred tem. 
Slovani so besedje prevzemali v večini primerov iz stare visoke nemščine ali njene predhodne faze.

Zahodnogermanske izposojenke v praslovanščini izkazujejo naslednja pravila nadomestnega glasoslovja: zgerm. ${ }^{*} \bar{o} \rightarrow$ psl. ${ }^{*} u_{2}$ (psl. *buky, ${ }^{*}$ plugz); zgerm. ${ }^{*} k i \rightarrow{ }^{*} c b$ (psl. *cbrky); zgerm. ${ }^{*} E N C,{ }^{*} O N C \rightarrow$ psl. ${ }^{*} C C,{ }^{*} C$ (psl. *pěnęzb, *troba); zgerm. *ing $\rightarrow$ psl. *ez (psl. *pěnęzb); zgerm. *ū $\rightarrow$ psl. *y (psl. *myto); zgerm. $*_{a} \rightarrow$ psl. ${ }^{*} o\left(\right.$ psl. $*_{p o p}$ ); zgerm. $*_{i}, *_{u} \rightarrow$ psl. $*_{b}, *_{b}$ (psl. *kbbblb); zgerm. ${ }^{*} a R C \rightarrow$ psl. ${ }^{*} o R C$ (psl. *korlb); zgerm. ${ }^{*} f \rightarrow$ psl. ${ }^{*} p$ (psl. *pila), stvn. pf $\rightarrow$ psl. ${ }^{*} p$ (psl. *korpb); stvn. $s\left[{ }^{*}{ }^{*}\right.$, $\left.*_{z}\right] \rightarrow$ psl. *̌s, *ž (psl. *xyša/*xyža), stvn. ss $\left[*^{*}\right.$ s $] \rightarrow$ psl. *̌s (psl. *mbša), stvn. sk [sk > šk] $\rightarrow$ psl. *sk, *̌sk (psl. *skrini, *škoda). Nadomeščanje zahodnogermanskih glasov s praslovanskimi kaže na to, da je med slovansko-gotskimi in slovansko-zahodnogermanskimi jezikovnimi stiki v praslovanščini že prišlo do nekaterih glasovnih sprememb. 11

Zahodnogermanske izposojenke spadajo v naslednja pomenska polja:

[a] oblast in vojska: zgerm. *kuning ( $>$ stsaš. kuning, stvn. chuning) $\rightarrow$ psl. *kbnęzb 'knez' (> sln. knệz); stvn. Karl $\rightarrow$ psl. *korlb 'kralj' (> sln. králj);

[b] trgovina in denar: zgerm. *penning ( $>$ stsaš. penning, stvn. pfenning) $\rightarrow$ psl. *pěnęzb 'denar' (> sln. pệnez); bav. stvn. mūta $\rightarrow$ psl. *myto 'plačilo' (> sln. mîto $\rightarrow$ mitnîna);

[c] predmeti za shranjevanje: zgerm. *budinō (> stsaš. budin, stvn. butin $) \rightarrow$ psl. *bъdbńb, *bbdbńa 'vrsta posode' (> sln. badänj); stvn. kubilo $\rightarrow$ psl. *kbbblb 'vrsta posode' (> sln. kabäl); stvn. lāge $\rightarrow$ psl. *lagy, Asg *lagbvb 'steklenica'; stvn. scrīni $\rightarrow$ psl. *skrini, Gsg *skrińe 'skrinja' ( $\rightarrow$ sln. skrínja); stvn. stampf $\rightarrow$ psl. *stopa 'možnar' (> sln. stọpa);

[č] deli naselij, stavbe in imetje: stvn. hūs 'hiša' $\rightarrow$ psl. *xyša/*xyža 'hiša' (> sln. híša, híža);

[d] tehnična terminologija: zgerm. ${ }^{*}$ plōg ( $>$ srspn. ploch, stvn. pfluoc) $\rightarrow$ psl. *plugb 'plug' (> sln. plûg/plüg); zgerm. *fïlō (> stsaš. fìla, stvn. fïla $) \rightarrow$ psl. *pila 'pila' (> sln. píla); zgerm. *wāgō (> stsaš. wāga, stvn. wāga) $\rightarrow$ sl. *vaga 'tehtnica' (> sln. vâga);

[e] krščanska terminologija: zgerm. *kir(i)kō (> stsaš. kirika, stvn. kirihha) $\rightarrow$ psl. *cbrky, Asg *cbrkbvb 'cerkev' (> sln. cẹ́rkav); stvn. munih $\rightarrow$ psl. *mъnixъ 'menih, redovnik' ( $>$ sln. mənïh); stvn. pfaffo $\rightarrow$ psl. *pops 'duhovnik' (> sln. pöp); stvn. fasta $\rightarrow$ psl. *postb 'post' ( $>$ sln. pöst); stvn. missa $\rightarrow$ psl. *mbša 'maša' (> sln. máša); stvn. altāri $\rightarrow$ sl. *oltaŕb 'oltar' (> sln. oltár);

[f] ostalo: zgerm. *bōkō (> stsaš. bōka, stvn. buohha) $\rightarrow$ psl. *buky, Asg *bukъvb 'bukev' (> sln. búkəv); stvn. karpf(o) $\rightarrow$ psl. *korps 'krap' (> sln. kräp); zgstvn. raubian (> stvn. roubōn) $\rightarrow$ psl. rubiti 'rubiti' (> sln. rubīti/rúbiti); stvn. scado $\rightarrow$ psl. *škoda ‘škoda' (> sln. škọda); stvn. trumba $\rightarrow$ psl. *troba 'troba, trobenta' (> sln. trọ́ba); stvn. affo $\rightarrow$ psl. *ops 'opica' ( $\rightarrow$ sln. ọpica).

11 Zelo verjetno je, da je bila v času izposojanja iz zahodnogermanskih jezikov v praslovanščino praslovanska monoftongizacija diftongov že $\mathrm{v}$ teku in da je bil novi praslovanski $* u_{2} \mathrm{C}<* a u C$ glasovno najbližji zahodnogermanskemu * $\bar{o}$. 
Starovisokonemške izposojenke v praslovanščini se pojavljajo v vseh pomenskih poljih kot gotske izposojenke s to razliko, da se besedje iz stare visoke nemščine pojavlja še na področju krščanske in tehnične terminologije. To je razumljivo, saj so zahodni in zahodni južni Slovani krščanstvo prejeli preko Bavarcev oz. Frankov.

\section{STAROVISOKONEMŠKE IZPOSOJENKE V ALPSKI SLOVANŠČINI IN ZGODNJI SLOVENŠČIINI}

Alpski Slovani so v še tesnejši stik z Bavarci in Franki prišli sredi 8. stoletja n. š., ko so si le-ti začeli podrejati alpskoslovanske kneževine: Karantanija (severno od Karavank, središče Krnski Grad / Kranburg; prva omemba ok. 664 kot Carantanum ( $\rightarrow$ sl. *Korqtanı $>$ sln. Korotän 'Korotan, Koroška')) je bila Bavarski priključena v letih 743-745, Karniola (južno od Karavank, središče Carnium ( $\rightarrow$ sl. *Korńb > sln. Kránj 'Kranj, Kranjska'), današnji Kranj; prva omemba ok. 738 kot Carniola) pa frankovski državi (Bavarska je bila frankovski državi priključena leta 788) v času frankovsko-avarskih vojn 791 in 795-796. Slovanski jezik v vzhodnih Alpah je tako prišel v stik s staro (bavarsko) visoko nemščino (izpričana v obdobju 750-1050). S stališča slovanščine je za to obdobje smiselno razlikovati dva slovanska hronolekta, in sicer alpsko slovanščino, tj. slovanski jezik v vzhodnih Alpah do 9. stoletja (do ok. 800), in zgodnjo slovenščino, ki se je iz alpske slovanščine začela oblikovati v 9. in 10. stoletju (ok. 800-1000).

\subsection{Starovisokonemške izposojenke v alpski slovanščini}

Starovisokonemške izposojenke v alpski slovanščini (do ok. 800 n. š.) podobno kot izposojenke na ostalem slovanskem jezikovnem ozemlju v tem času izkazujejo glasovni sistem praslovanskega tipa, toda $\mathrm{z}$ nekoliko mlajšimi pojavi.12 Značilne pa so bile samo za alpsko slovanščino, tj. pojavljajo se samo v slovenščini. Pomenska polja tega besedja se bistveno ne ločijo od pomenskih polj splošnoslovansko prevzetega besedja:

[a] predmeti za shranjevanje: stvn. pfanna $\rightarrow$ sl. *pony, Asg *ponzvb $>$ sln. pónəv;

[b] deli naselij, stavbe in imetja: stvn. $\operatorname{scugin}(a) \rightarrow$ sl. ${ }^{*} s k b d b n ́ b>\operatorname{sln}$. skadänj skadnjä> skadänj skagnjä $\geq$ skagänj skagnjä;13

[c] krščanska terminologija: frank. stvn. abbat : bav. stvn. *appāt $\rightarrow$ sl. *opatb $>$ sln. opât; stvn. (gi)fatero $\rightarrow$ sl. *botrb > sln. bọtar; stvn. jungiro 'mlajši' $\rightarrow$ sl. *jogbrb > sln. jọgar 'učenec, apostol';

[č] drugo: stvn. kërvol(l)a, *kërvulla $\rightarrow$ sl. *kerbuĺa $>$ sln. krebúlja 'rastlina Anthriscus caerefolium'; stvn. wërd $\rightarrow$ sl. *verd-bnъ $>$ sln. vrẹ́don; stvn. *wunskjan $(>$ wunscen $) \rightarrow \mathrm{sl}$. *vQščiti > sln. voščīti/vóšččiti.

12 V primerjavi z (morda nekoliko starejšimi) »praslovanskimi« izposojenkami se v alpski slovanščini npr. mehkonebniki $k, g, x$ že lahko pojavljajo v položaju pred sprednjimi samoglasniki in se ne palatalizirajo (psl. *kerbula).

13 Ramovš 1924: 275; ESSJ III: 241-242. 


\subsection{Starovisokonemške izposojenke $\mathrm{v}$ zgodnji slovenščini}

Starovisokonemške izposojenke v zgodnji slovenščini (ok. 800-1050) ne izkazujejo več glasovnega sistema praslovanskega tipa (fonetične substitucije so npr. tele: stvn. $k^{E}, g^{E}, x^{E} \rightarrow \sin . k, g, x$; stvn. $E N C, O N C \rightarrow \operatorname{sln} . E N C, O N C$; stvn. $\bar{u}$ $\rightarrow \operatorname{sln} . u$; stvn. $a \rightarrow \operatorname{sln} . a$; stvn. $i, u \rightarrow \operatorname{sln} . i, u$. Izposojenke se pojavljajo v naslednjih pomenskih poljih (ker so Alpski Slovani krščanstvo prejeli preko Bavarcev, je med njimi opazno izrazje s področja krščanstva):

[a] cerkveno in versko življenje: stvn. biscof $\rightarrow$ sln. *pškof $>$ šköf; stvn. fimfchus$t i \rightarrow$ sln. bînkošti; stvn. firmōn $\rightarrow$ sln. bîrmati; stvn. sëgan (> srvn. sëgen)

$\rightarrow$ sln. žégan 'blagoslov', žégnati 'blagosloviti';

[b] predmeti za shranjevanje: stvn. skaf, skaph $\rightarrow$ sln. škäf;

[c] gradnja, stanovanjska oprema, orodje: stvn. saga $\rightarrow$ sln. žâga; frank. stvn. zimbar : bav. stvn. *zimpar $\rightarrow$ sln. cimpar 'ostrešje'; frank. stvn. zimbarman : bav. stvn. zimparman $\rightarrow$ sln. cimporman 'tesar'; frank. stvn. swëbal, swëval : bav. stvn. *swëpal $\rightarrow \operatorname{sln}$. žvéplo; stvn. scāri $\rightarrow$ sln. škârje;

[̌̌] gospodinjstvo (oblačila, posoda, hrana, domače zdravilstvo): stvn. flëc (> srvn. vlëc) $\rightarrow$ sln. blëk 'zaplata';

[d] drugo: stvn. fazzōn, srvn. vazzen $\rightarrow$ sln. básati 'tlačiti, nakladati'; frank. stvn. roubōn : bav. stvn. roupōn $\rightarrow$ sln. rộpati; stvn. scrato $\rightarrow$ sln. škrät; frank. stvn. truha : bav. stvn. truya $\rightarrow$ nar. sln. trúga 'krsta'; stvn. slahta (> srvn. slaht(e)) $\rightarrow$ nar. sln. žlâhta 'sorodstvo'.

Starovisokonemške izposojenke so značilne za veliko večino slovenskega jezikovnega ozemlja. Ker v 19. stoletju zaradi glasovne oddaljenosti od sodobne nemščine niso bile več občutene kot nemške, so bile v veliki večini sprejete tudi v knjižno slovenščino. Le nekatere med njimi danes ne spadajo v knjižni jezik (básati, blëk, cimpar, cimparman, žégən, žégnati, žlâhta).

\section{REDNJEVISOKONEMŠKE IZPOSOJENKE V SLOVENŠČINI}

Kot posledica zgodovinskih okoliščin, kot so bile fevdalizacija (začetki v 9. stoletju, višek v drugi polovici 10. stoletja in v 11. stoletju), »velika« nemška kolonizacija (10.-12. stoletje), ustanavljanje samostanov (od 11. stoletja), nastajanje gradov (od druge polovice 12. stoletja) in ustanavljanje mest (od 13. stoletja), se je nemško-slovenski jezikovni stik v visokem in poznem srednjem veku zelo okrepil, saj so bili ti procesi povezani z doseljevanjem nemško govorečega prebivalstva na prvotno slovensko jezikovno ozemlje. $Z$ novo zunajjezikovno stvarnostjo, tj. novo civilizacijsko pridobitvijo, povezano $\mathrm{z}$ mestom, gradom ali samostanom, je $\mathrm{v}$ slovenščino prišlo tudi novo poimenovanje zanjo, ki je bilo seveda nemško. To so t. i. kulturne izposojenke, ki so posledica »modernizacije življenjskih odnosov«, katerega središče je bilo navadno predvsem nemško govoreče mesto, ki je slovensko govorečemu podeželju posredovalo besedje s področja cerkvenega življenja, 
uprave, trgovine in obrti v obliki cehovstva (tehnično izrazje, poimenovanja za poklice).14 Poleg izposojenk zunaj osnovnega besedja se je v omejeni meri izposojalo tudi osnovno besedje (predvsem načinovni prislovi in členki). V tem obdobju so nemške izposojenke slovenščino dobesedno preplavile.

Ker so se od stare do srednje visoke nemščine zgodile nekatere značilne glasovne spremembe, se tudi srednjevisokonemške izposojenke od starovisokonemških izposojenk ločijo po svojih glasovnih značilnostih. Najznačilnejše glasovne spremembe v bavarski srednji visoki nemščini in glasovnega nadomeščanja bavarskih srednjevisokonemških glasov v slovenščini so: (a) samoglasniki: srvn. $\bar{l}>e i$ (ok. 1100) > ai (ok. $1250) \rightarrow \operatorname{sln} . i:$ ej $: a i$ (srvn. *rīde $\rightarrow \operatorname{sln}$. rída : rệjda : râjda 'serpentina, vijuga'); srvn. $\bar{u}>o u($ ok. 1100) $>a u($ ok. 1250) $\rightarrow \operatorname{sln} . u: o v: a v($ srvn. rüt $\rightarrow \operatorname{sln}$. rût $:$ rộvt $:$ râvt 'rovt, ledina'); bav. srvn. $a / \bar{a}>o / \bar{o}$ (ok. 1200) $\rightarrow$ sln. $a: o$ (bav. srvn. *pharrehūs $\rightarrow$ sln. fárovž 'župnišče' : bav. srvn. wagener $>$ *wogener $\rightarrow$ sln. bógnar 'kolar'); (b) soglasniki: srvn. $\breve{s} k>\check{s}$ (ok. 1100) $\rightarrow \operatorname{sln} . \check{s} k: \check{s}$ (srvn. schaf $\rightarrow \operatorname{sln}$. škäf : srvn. schenken $\rightarrow$ sln. šẹnkati 'podariti, pokloniti'); srvn. $p f \rightarrow \operatorname{sln} . p($ do 1100) $: f(\operatorname{od} 1100)$ (srvn. schupfe $\rightarrow \operatorname{sln}$. šüpa 'lopa, kolnica' : srvn. pharre $\rightarrow \operatorname{sln}$. fára ‘župnija'); srvn. $v$ $>f($ ok. 1200$) \rightarrow \operatorname{sln} . b: f$ (srvn. vazzen $\rightarrow \operatorname{sln}$. básati 'tlačiti, nakladati' : fâsati 'prejeti, dobiti'); srvn. $u>w($ ok. 1100) $>v($ ok. 1200) $\rightarrow \operatorname{sln} . v: b: v$ (srvn. wïhennahten $\rightarrow$ sln. vẹ́nahti 'božič' : srvn. wirt $\rightarrow \operatorname{sln}$. bîrt 'gostitelj, gospodar, gostilničar').

Izposojenke iz (bavarske) srednje visoke nemščine (dokumentirana v obdobju od ok. 1050 do ok. 1350) v slovenščino je mogoče dokumentirati v vseh pomenskih poljih. Pri tem ne gre samo za izposojenke, ki so v slovenščino prišle z novo zunajjezikovno stvarnostjo, temveč tudi za besedje, ki je izpodrivalo domača poimenovanja. Izposojenke iz (bavarske) srednje visoke nemščine je mogoče razdeliti v naslednje pomenske skupine:

[a] cerkveno in versko življenje: srvn. pharre $\rightarrow$ sln. fára 'župnija'; bav. srvn. *pharrehūs $\rightarrow$ sln. fárovž 'župnišče'; bav. srvn. pharr $\rightarrow$ sln. fâr 'župnik'; bav. srvn. *pharremeister $\rightarrow \operatorname{sln}$. fármoštər $\geq$ fájmoštar 'župnik'; srvn. mesnære $\rightarrow$ sln. mẹžnar 'cerkovnik'; srvn. turn $\rightarrow$ sln. túrən 'cerkveni stolp, zvonik'; srvn. vrīthof $\rightarrow$ sln. brîtof 'pokopališče'; frank. srvn. bāre : bav. srvn. *pāre $\rightarrow$ sln. pāre 'mrtvaški oder'; srvn. jārmark $\rightarrow$ sln. jarmark '(letni) sejem'; frank. srvn. bërhtnaht : bav. srvn. përhtnaht $\rightarrow$ sln. pérnahti 'sveti trije kralji'; srvn. wīhennahten $\rightarrow \operatorname{sln}$. vẹnahti 'božič'; srvn. opfer $\rightarrow \operatorname{sln}$. óf potrebe'; srvn. bredige, predige $\rightarrow$ sln. prídiga; srvn. wìse $\rightarrow \operatorname{sln}$. vîža 'način; napev, melodija';

[b] življenje na vasi in v mestu: srvn. grunt $\rightarrow$ sln. grünt 'posestvo'; srvn. gemeine $\rightarrow$ sln. gmâjna 'neobdelan svet, last vaške skupnosti, občina'; srvn. rūt $\rightarrow \operatorname{sln}$. rût, rộvt, râvt 'rovt, ledina'; frank. srvn. burgære > burger : bav. srvn. purger $\rightarrow$ sln. pūrgar 'meščan'; frank. srvn. rāthūs : bav. srvn. *rōthous $\rightarrow$ sln. rộtovž 'mestna hiša'; srvn. schoule $\rightarrow$ sln. šộla;

14 Pojem kulturna izposojenka je definiran npr. v Bayer 2006: 65-68. 
[c] poklici in dejavnosti: frank. srvn. wagener : bav. srvn. *wogener $\rightarrow$ sln. bọgnar 'kolar'; srvn. mālære $\rightarrow$ sln. mâlar 'pleskar, slikar'; frank. srvn. badære : bav. srvn. padære $\rightarrow$ sln. pâdar 'zdravilec, zdravnik'; frank. srvn. becke : bav. srvn. peck $\rightarrow$ sln. pệ; srvn. rihtære $>$ rihter $\rightarrow$ sln. ríhtar 'sodnik'; srvn. schuoster $\rightarrow$ sln. šûštar, šộštar 'čevljar'; spsrvn. tischler $\rightarrow$ sln. tíšljar 'mizar'; srvn. wirt $\rightarrow$ sln. bîrt 'gostitelj, gospodar, gostilničar'; srvn. snīdære $>$ snīder $\rightarrow$ sln. žnîdar 'krojač'; srvn. soldenære $>$ soldner $>$ solner $\rightarrow \operatorname{sln}$. žolnir 'vojak';

[̌̌] hiša: srvn. ziegel $\rightarrow$ sln. cệgal 'opeka'; srvn. zwëc $\rightarrow$ sln. cvëk 'žebelj'; srvn. $d r \bar{a} t \rightarrow \operatorname{sln}$. drât, drột 'žica'; bav. srvn. *gerust $\rightarrow$ sln. grüšt 'zidarski oder'; frank. srvn. bant : bav. srvn. pant $\rightarrow$ sln. pänt 'podboj'; srvn. trām $\rightarrow$ sln. trâm; srvn. ganc $\rightarrow$ sln. gànk 'pokrit lesen hodnik, balkon, gank'; srvn. $k a-$ mer $(e) \rightarrow$ sln. kâmra 'soba'; srvn. kaste $\rightarrow$ sln. kášča, kâšta 'shramba', käšt 'podstrešje'; 15 frank. srvn. *badstube > batstube : bav. srvn. *patstube $\rightarrow \operatorname{sln}$. pâštuba, pajjštva 'stavba za sušenje lanu, sadja'; frank. srvn. schībe : bav. srvn. schīpe $\rightarrow$ sln. šipa; srvn. schupfe $\rightarrow$ sln. šüpa 'lopa, kolnica'; srvn. stëge, stiege $\rightarrow$ sln. štệnga 'stopnica'; srvn. polster $\rightarrow$ sln. pọ́vštər 'blazina, vzglavnik'; srvn. *rīde $\rightarrow$ sln. rída, rệjda, râjda 'serpentina, vijuga';

[d] orodje: srvn. vackel $\rightarrow \operatorname{sln}$. bâkla; srvn. furkel $\rightarrow$ sln. bûrklja; srvn. geisel $\rightarrow$ sln. gâjžlja 'bič'; frank. srvn. bühse : bav. srvn. puhse $\rightarrow$ sln. pûška; srvn. sackel $\rightarrow \operatorname{sln}$. žákalj, srvn. snuor $\rightarrow \operatorname{sln}$. žnộra 'vrv, vrvica';

[e] obleka: srvn. arssack $\rightarrow$ sln. âržet 'žep'; srvn. vürtuoch $\rightarrow$ sln. birtah, firtah 'predpasnik'; srvn. gewant $\rightarrow$ sln. gvänt 'obleka'; srvn. kittel $\rightarrow$ sln. kiklja '(žensko) krilo'; srvn. samīt, samāt $\rightarrow \operatorname{sln}$. žámet; srvn. sìda $\rightarrow$ sln. žîda 'svila';

[f] posoda: srvn. glas $\rightarrow$ sln. gläž 'steklo; kozarec'; srvn. vlasche $\rightarrow$ sln. fláša 'steklenica'; srvn. phister $\rightarrow$ sln. pískar 'lonec'; frank. srvn. büt(t)e : bav. srvn. pūt(t)e $\rightarrow$ sln. púta 'brenta'; stvn. prëssa $\rightarrow$ sln. prẹša; srvn. rībīsen $\rightarrow \operatorname{sln}$. rîbeř $(\partial n)$;

[g] hrana: srvn. riht(e) $\rightarrow$ sln. rîhta 'jed'; srvn. smac, smach $\rightarrow$ sln. žmäh 'okus'; srvn. phanzëlte $\rightarrow \operatorname{sln}$. fancelt $\geq$ fláncat; srvn. ezzīh $\rightarrow$ sln. jẹsih 'kis, ocet'; frank. srvn. brāte : bav. srvn. prāte $\rightarrow$ sln. prâta 'pečenka'; frank. srvn. buter: bav. srvn. puter $\rightarrow$ sln. pútar 'maslo'; srvn. rīs $\rightarrow$ sln. rî̌z; frank. srvn. spëk: bav. srvn. spëch $\rightarrow$ sln. špëh 'slanina'; srvn. smalz $\rightarrow$ sln. žmälc [žmäucc] 'raztopljena in za uporabo hranjena svinjska mast'; srvn. sulze $\rightarrow$ sln. žộlca [žộuca]; srvn. suppe $\rightarrow$ sln. žúpa 'juha';

[h] kulturne, užitne in okrasne rastline: srvn. heiden $\rightarrow$ sln. âjda; frank. srvn. veige $:$ bav. srvn. *pfìge $\rightarrow$ sln. fíga; srvn. nagellīn, negellīn $\rightarrow$ sln. nágalj; srvn. nëspel $\rightarrow$ sln. nệsplja; frank. srvn. buhsboum : bav. srvn. puhspām $\rightarrow \operatorname{sln}$. püšpan; srvn. snit(e)louch $\rightarrow$ sln. žnitlah, šnitlah 'drobnjak'; srvn. safrān $\rightarrow$ sln. žafrân; srvn. salbeia $\rightarrow$ sln. žájbalj;

15 O nadomeščanju stvn. $\check{s} t \rightarrow \operatorname{sln} . \check{s} \check{c}: \check{s} t$ prim. Ramovš 1924: 273. 
[i] telo, osebna higiena, zdravje: srvn. krage $\rightarrow$ sln. krágən 'vrat'; srvn. arzenie $\rightarrow$ sln. arcnîja 'zdravilo'; srvn. pflaster $\rightarrow$ sln. fláštzr 'obliž'; srvn. seife $\rightarrow$ sln. žâjfa 'milo'; srvn. salbe $\rightarrow \operatorname{sln}$. žâvba 'mazilo';

[j] družina: frank. srvn. buobe : bav. srvn. puobe $\rightarrow$ sln. pộb 'fant'; srvn. swāger $\rightarrow$ sln. švágar 'svak';

[k] dejanja: srvn. volgen $\rightarrow$ sln. bộvgati > bộgati; frank. srvn. zoubern : bav. srvn. zoupern $\rightarrow \operatorname{sln}$. cọprati 'čarati'; srvn. vazzen $\rightarrow \operatorname{sln}$. fâsati 'prejeti, dobiti'; srvn. vëhten $\rightarrow \operatorname{sln}$. fẹhtati 'prostiti'; srvn. rīben $\rightarrow$ sln. rîbati; srvn. rouben $\rightarrow \operatorname{sln}$. rávbati 'pleniti'; srvn. schenken $\rightarrow \operatorname{sln}$. šệnkati 'podariti, pokloniti'; srvn. spot $\rightarrow \operatorname{sln}$. špöt 'posmeh, zasmeh', špọtati 'posmehovati se, zasmehovati';

[I] pridevniki, načinovni prislovi: srvn. valsch $\rightarrow$ sln. fâvš, fộv̌̌ 'napačen; nevoščljiv'; srvn. gelīch $>$ glīch $\rightarrow$ sln. glîh 'enak'; srvn. sicher $\rightarrow$ sln. žihor 'gotov';

[m] drugo: srvn. sleht $\rightarrow$ sln. žlëht 'hudoben, zloben'; srvn. luft $\rightarrow$ sln. lüft 'zrak'; srvn. sūber $\rightarrow \operatorname{sln}$. žâvbar(n), zâvbar 'lep'; srvn. mūle $\rightarrow$ sln. múla 'obraz slabe volje, kujanje'; bav. srvn. tūsent $\rightarrow$ sln. tâvžənt 'tisoč' .

Podobno kot starovisokonemške so (bile) tudi srednjevisokonemške izposojenke razširjene v večini slovenskih narečij. Kljub temu pa v procesu standardizacije v knjižno slovenščino razen redkih izjem (âjda, bâkla, u-bộgati, fíga, nágalj, nệšplja, pệk, prídiga, pûška, pūšpan, rîž, škäf, šộla, trâm, žafrân, žájbalj, žákalj, žámet, žọlca) praviloma niso bile sprejete.

\section{NOVOVISOKONEMŠKE IZPOSOJENIKE V SLOVENŠČINI}

Proces prevzemanja iz nemščine v slovenščino, ki se je utrdil v visokem in poznem srednjem veku, se je nadaljeval tudi v novem veku. $\mathrm{V}$ novovisokonemškem obdobju (od ok. 1350 dalje) so nemške prevzete besede v slovenščino prišle tako iz ljudskega jezika, tj. iz narečij, kot iz knjižnega jezika. Ker je novovisokonemškega besedja v slovenščini ogromno in je (z izjemo tujk iz knjižnega jezika, ki poimenujejo pojme učene kulture) prisotno v podobnih semantičnih poljih kot srednjevisokonemško besedje, je tu proces prevzemanje prikazan samo na nekaj zgledih.

\subsection{Ljudske novovisokonemšlke izposojenke v slovenščini}

Ljudske novovisokonemske izposojenke so v ljudsko slovenščino, tj. slovenska narečja, prišle z neposrednim jezikovnim stikom slovensko govorečih z nemško govorečimi in so značilne za celotno obdobje novega veka. Zanje je glede na jezikovne značilnosti ljudske nemščine mogoče reči, da so prevzete iz južne bavarske nove visoke nemščine, samo v nekaterih primerih je glede na razširjenost kakega leksema v različnih južnobavarskih narečjih mogoče natančneje ločiti tudi posamezna sodobna avstrijska južnobavarska narečja, kot so koroško, štajersko in tirolsko narečje. 
Ljudske novovisokonemške izposojenke v slovenščini izkazujejo glasovne značilnosti južne bavarske visoke nemščine (med katerimi so nekatere nastale že v stari ali srednji bavarski visoki nemščini), natančneje južnokoroških narečij. Najznačilnejše med njimi, prikazane primerjalno s knjižno nemščino, so:16 bav. stvn. $b-, d-, g->p-, t-, k$ - (nem. Bild $:$ nar. Pild $\rightarrow$ sln. pild 'slika, podoba'; nem. $D u$ sche $:$ nar. Tusch $\rightarrow$ sln. tû̌s; nem. Gesicht : nar. Ksicht $\rightarrow$ sln. ksîht 'obraz'); bav. srvn. $a / \bar{a}>o / \bar{o}$ (nem. schwach : nar. schwoch $\rightarrow$ sln. žboh, švoh 'slaboten'); srvn. $i u, \bar{u}>$ nar. nem. ai (nem. Feuerzeug : nar. Faierzaig $\rightarrow$ sln. fajarcajg, faracajg 'vžigalnik'); srvn. ei $>a i>$ nar. nem. $\bar{a}$ (nem. teilen $:$ nar. tāln $\rightarrow$ sln. tálati 'deliti'); srvn. ou $>a u>$ nar. nem. $\bar{a}$ (nem. Baum : nar. Pām $\rightarrow$ sln. pam 'drevo, deblo'); srvn. $\ddot{u} / \bar{u}>i / \bar{\imath}$ (nem. Kübel $:$ nar. Kībl $\rightarrow$ sln. kîblja 'vedro'); srvn. $\ddot{o} / \ddot{o}>$ nar. nem. e/e (nem. bügeln, nar. pögeln $>$ pēgeln $\rightarrow$ sln. peglati 'likati'); srvn. $\ddot{a} / \bar{a}>$ nar. nem. $a / \bar{a}$ (nem. Teller : nar. Täller $>$ Taller $\rightarrow$ sln. táler 'krožnik').

\subsection{Knjižne novovisokonemške izposojenke $\mathrm{v}$ slovenščini}

Učene novovisokonemške tujke so v knjižno slovenščino prišle iz knjižne nemščine preko t. i. učene kulture. Značilne so predvsem za 19. in 20. stoletje, ko je slovenščina preko nemščine prevzela tudi večino evropskih tujk (med katerimi je večina grško-latinskega izvora), t. i. evropeizmov. Če so bile ljudske novovisokonemške izposojenke $\mathrm{v}$ slovenskem knjižnem jeziku zaradi purističnih teženj $\mathrm{v}$ procesu standardizacije skoraj v celoti nadomeščene $\mathrm{z}$ manj razširjenimi domačimi slovenskimi besedami ali slavizmi ( $\mathrm{tj}$. $\mathrm{z}$ besedami, ki so bile prevzete iz drugih knjižnih slovanskih jezikov), pa je od druge polovice 19. stoletja v slovenski knjižni jezik in iz njega v slovenska narečja, ki so v stiku z njim, iz nemškega knjižnega jezika bilo sprejeto veliko učenih novovisokonemških tujk, ki so v uporabi še danes. Knjižna nemščina je bila torej vsaj do leta 1918 (delno pa tudi še do druge svetovne vojne) jezik posrednik, preko katerega je knjižna slovenščina sprejemala mednarodno in zelo razširjeno besedje iz evropskih jezikov. To pomeni, da so t. i. evropeizmi v slovenščino večinoma prišli preko nemščine (nem. Benzin $\rightarrow$ sln. bencîn; nem. Kassette $\rightarrow$ sln. kasệta; nem. Stipendium $\rightarrow$ sln. štipẹ́ndija; nem. Vase $\rightarrow \operatorname{sln}$. váza; nem. Version $\rightarrow \operatorname{sln}$. vérzija; nem. Viadukt $\rightarrow \operatorname{sln}$. viadûkt; nem. Vulkan $\rightarrow$ vulkân).

\section{SKLEP}

Nemški kulturni vpliv na slovensko kulturo in posledično vpliv nemščine na slovenščino se je začel v času po političnoupravni priključitvi alpskoslovanskih (staroslovenskih) kneževin Karantanije in Karniole vojvodini Bavarski oz. frankovski državi v drugi polovici 8. stoletja ter začel v osrednjeslovenskem prostoru (ne pa tudi na južnem Koroškem in južnem robu Štajerske, ki sta ostala v

16 Glasovne značilnosti posameznih bavarskih narečij so prikazane v Kranzmayer 1956. 
okviru Avstrije) pojemati po letu 1918, ko je večji del slovenskega jezikovnega ozemlja prišel v jugoslovanski političnoupravni okvir. Slovenska kultura je (bila) tako več kot tisoč let v intenzivnem stiku z nemško govorečo kulturo, slovenski jezik pa ves ta čas intenzivno pod vplivom nemškega. V zgodovini je ves čas prihajalo do prevzemanja besedja iz narečne nemščine, in sicer južne bavarske visoke nemščine oz. njenih časovnih različic (to so stara, srednja in nova južna bavarska visoka nemščina) v narečno slovenščino, v moderni dobi (predvsem v 19. in v prvi polovici 20. stoletja) pa tudi iz knjižne nemščine v knjižno slovenščino. $\mathrm{V}$ drugi polovici 20. in v 21. stoletju je vpliv nemške kulture in nemškega jezika v (osrednje)slovenskem prostoru precej zmanjšan in je primerljiv z vplivom drugih evropskih jezikov in kultur (z izjemo globalne angloameriške kulture in njenega globalnega jezika - angleščine).

$\begin{array}{ll}\text { KRAJŠAVE } \\ \text { bav. } & \text { bavarsko } \\ \text { frank. } & \text { frankovsko } \\ \text { got. } & \text { gotsko } \\ \text { nar. } & \text { narečno } \\ \text { nem. } & \text { (novovisoko)nemško } \\ \text { psl. } & \text { praslovansko } \\ \text { sl. } & \text { slovansko } \\ \text { sln. } & \text { slovensko } \\ \text { spsrvn. } & \text { spodnjesrednjevisokonemško } \\ \text { srvn. } & \text { srednjevisokonemško } \\ \text { stsaš. } & \text { starosaško } \\ \text { stvn. } & \text { starovisokonemško } \\ \text { zgerm. } & \text { zahodnogermansko } \\ \text { zgot } & \text { zahodnozgotsko } \\ \text { zgstvn. } & \text { zgodnje starovisokonemško }\end{array}$

LITERATURA

Bayer 2006 = Markus Bayer, Sprachkontakt deutsch-slavisch: eine kontrastive Interferenzstudie am Beispiel des Ober- und Niedersorbischen, Kärntnerslovenischen und Burgenlandkroatischen, Frankfurt am Main: Peter Lang, 2006 (Berliner Slawistische Arbeiten 17).

Bichlmeier 2010 = Harald Bichlmeier, Rōma - Namenkundlich-sprachhistorische Anmerkungen zu einem allgemein bekannten Ortsnamen, Das Altertum 55 (2010), 175-202.

Braune 1987 = Wilhelm Braune, Althochdeutsche Grammatik, bearbeitet von Hans Eggers, Tübingen: Max Niemeyer Verlag, ${ }^{14} 1987$.

Breznik 1906 = Anton Breznik, O tujkah in izposojenkah, Dom in svet 18 (1906), 149-154. (Ponatis v: Anton Breznik, Jezikoslovne razprave, izbral in uredil Jože Toporišič, Ljubljana: Slovenska matica, 1982, 365-370.)

ESSJ I-V = France Bezlaj, Etimološki slovar slovenskega jezika I-V, Ljubljana: Mladinska knjiga oz. Založba ZRC, 1976, 1982, 1995, 2005, 2007.

Furlan 2013 = Metka Furlan, Novi etimološki slovar slovenskega jezika: poskusni zvezek, Ljubljana: Inštitut za slovenski jezik ZRC SAZU - Založba ZRC, 2013.

Furlan 2014 = Metka Furlan, Slovarska monografija Hildegard Striedter-Temps Deutsche Lehnwörter im Slovenischen (1963) v luči Bezlajeve kritike (1964) - petdeset let pozneje, Jezikoslovni zapiski 20 (2014), št. 1, 25-42. 
Grafenauer 1923 = Ivan Grafenauer, Naglas v nemških izposojenkah v slovenščini (Donesek k zgodovini slovenskega naglasa), Razprave Znanstvenega društva za humanistične vede v Ljubljani 1 (1923), 358-391.

Holzer 2008 = Georg Holzer, Namenkundliche Aufsätze, Wien: Praesens Verlag, 2008 (Innsbrucker Beiträge zur Onomastik 4).

Jazbec 2007 = Helena Jazbec, Nemške izposojenke pri Trubarju: na primeru besedila Ena dolga predguvor, Ljubljana: Založba ZRC, ZRC SAZU, 2007 (Linguistica et philologica 17).

Kiparsky 1934 = Valentin Kiparsky, Die gemeinslavischen Lehnwörter aus dem Germanischen, Helsinki: Druckerei der Finnischen Literaturgesellschaft, 1934 (Annales Academiae scientiarum Fennicae, B XXXII, 2).

Kluge 1999 = Friedrich Kluge, Etymologisches Wörterbuch der deutschen Sprache, Berlin - New York: Walter de Gruyter, 231999 (11883).

Kos 1955 = Milko Kos, Zgodovina Slovencev od naselitve do petnajstega stoletja, Ljubljana: Slovenska matica, 1955.

König 1998 = Werner König, DTV-Atlas: deutsche Sprache, München: Deutscher Taschenbuch Verlag, 121998 (11978).

Kranzmayer 1956 = Eberhard Kranzmayer, Historische Lautgeographie des gesamtbairischen Dialektraumes, Wien: Österreichische Akademie der Wissenschaften, 1956.

Lexer 1992 = Matthias Lexer, Mittelhochdeutsches Taschenwörterbuch, Stuttgart: Wissenschaftliche Verlagsgesellschaft Stuttgart, 381992.

Miklošič 1867 = Franz Miklosich, Die Fremdwörter in den slavischen Sprachen, Wien: Kaiserlichkönigliche Hof- und Staatsdruckerei, 1867.

Paul 1989 = Hermann Paul, Mittelhochdeutsche Grammatik, überarbeitet von Peter Wiehl und Siegfried Grosse, Tübingen: Max Niemeyer Verlag, ${ }^{24} 1989$.

Pronk-Tiethoff $\mathbf{2 0 1 0}$ = Saskia Pronk-Tiethoff, Semantička polja germanskih posuđenica u praslavenskome, Rasprave instituta za hrvatski jezik i jezikoslovlje (Zagreb) 36 (2010), št. 2, 317327.

Pronk-Tiethoff 2012 = Saskia Pronk-Tiethoff, The Germanic loanwords in Proto-Slavic: Origin and accentuation, Leiden: Rodopi, 2012.

Ramovš 1924 = Fran Ramovš, Historična gramatika slovenskega jezika: II. Konzonantizem. Ljubljana: Znanstveno društvo za humanistične vede v Ljubljani, 1924.

Ramovš 1995 = Fran Ramovš, Kratka zgodovina slovenskega jezika I, Ljubljana: ZRC SAZU, 21995 (Zbirka ZRC 9) (11936).

Schützeichel 1995 = Rudolf Schützeichel, Althochdeutsches Wörterbuch, Tübingen: Max Niemeyer Verlag, ${ }^{5} 1995$.

Shevelov 1964 = George Y. Shevelov, A Prehistory of Slavic: The Historical Phonology of Common Slavic, Heidelberg: Carl Winter Universitätsverlag, 1964.

Siatkowski 2004 = Janusz Siatkowski, Studia nad wplywami obcymi w Ogólnostowiańskim atlasie językowym, Warszawa: Uniwersytet Warszawski, Wydział Polonistyki, Instytut Slawistyki Zachodniej i Południowej, 2004.

Siatkowski 2005 = Janusz Siatkowski, Stowiańskie nazwy wykonawców zawodów w historii i dialektach, Warszawa: Uniwersytet Warszawski, Wydział Polonistyki, Instytut Slawistyki Zachodniej i Południowej, 2005.

Snoj 2003 = Marko Snoj, Slovenski etimološki slovar, Ljubljana: Modrijan, 22003 (11997).

Snoj 2005 = Marko Snoj, O prevzetih besedah, tujkah in izposojenkah, Slovenski jezik / Slovene linguistic studies 5 (2005), 113-122.

Striedter-Temps 1963 = Hildegard Striedter-Temps, Deutsche Lehnwörter im Slovenischen, Wiesbaden: Otto Harrassowitz, 1963.

Šekli 2012 = Matej Šekli, Notranja delitev neprevzetega in prevzetega besedja v praslovanščini, v: Individualna in kolektivna dvojezičnost, ur. Petra Stankovska - Maria Wtorkowska - Jozef Pallay, Ljubljana: Znanstvena založba Filozofske fakultete, 2012 (Slavica Slovenica 1), 369-381.

Šekli 2014 = Matej Šekli, Primerjalno glasoslovje slovanskih jezikov 1: Od praindoevropščine do praslovanščine, Ljubljana: Znanstvena založba Filozofske fakultete, 2014. 
Štih - Simoniti 2009 = Peter Štih - Vasko Simoniti, Na stičišču svetov: slovenska zgodovina od prazgodovinskih kultur do konca 18. stoletja, Ljubljana: Modrijan, 2009.

WBMÖ = Wörterbuch der bairischen Mundarten in Österreich 1-4-, bearbeitet von Viktor Dollmayr und Eberhard Kranzmayer, Wien: Österreichische Akademie der Wissenschaften, 1963-1998-.

\section{SUMMARY}

\section{Semantic fields of German loanwords in Slovenian}

The German influence on Slovenian culture and, consequently, the influence of German on Slovenian started after the political administrative annexation of the Alpine Slavic (i.e. Old Slovenian) principalities of Carantania and Carniola to the Duchy of Bavaria (or the Kingdom of the Franks) in the second half of the eighth century. This influence began to diminish in the central Slovenian area after 1918, when the majority of Slovenian-language territory was integrated into the Yugoslav political framework. However, this was not the case in southern Carinthia and on the southern margins of Styria, which remained in present-day Austria. Thus, Slovenian culture, including the language, was heavily influenced through contact with German-speaking culture for more than a millennium. The borrowing of words from dialect German into dialect Slovenian mainly progressed from the southern Bavarian variant of High German and its chronolects (i.e. Old, Middle, and New Southern Bavarian High German). In the nineteenth century and in the first half of the twentieth century, borrowing into Standard Slovenian was additionally based on Standard German. Since the second half of the twentieth century, the influence of German culture and the German language has been much reduced in the (central) Slovenian area and can be compared to the influence of other European languages and cultures, except for the global Anglo-American culture and global English. 